TITLE:

\title{
Automated closed-chamber measurements of methane fluxes from intact leaves and trunk of Japanese cypress
}

\section{AUTHOR(S):}

Takahashi, Kenshi; Kosugi, Yoshiko; Kanazawa, Akito; Sakabe, Ayaka

\section{CITATION:}

Takahashi, Kenshi ...[et al]. Automated closed-chamber measurements of methane fluxes from intact leaves and trunk of Japanese cypress. Atmospheric Environment 2012, 51: 329-332

ISSUE DATE:

2012-05

URL:

http://hdl.handle.net/2433/154924

\section{RIGHT:}

(C) 2012 Elsevier Ltd.; This is not the published version. Please cite only the published version.; この論文は出版社版でありません。引用の際に は出版社版をご確認ご利用ください。 


\section{Automated closed chamber measurements of methane fluxes from intact leaves}

2 and trunk of Japanese cypress

3 Kenshi Takahashi $^{1^{*}}$, Yoshiko Kosugi ${ }^{2}$, Akito Kanazawa $^{2}$ and Ayaka Sakabe ${ }^{2}$

$4 \quad{ }^{1}$ Research Institute for Sustainable Humanosphere, Kyoto University, Gokasyo, Uji 611-0011, Japan

$5 \quad{ }^{2}$ Graduate School of Agriculture, Kyoto University, Kyoto 606-8502, Japan

* Corresponding author, E-mail: tkenshi@rish.kyoto-u.ac.jp

\section{ABSTRACT}

Continuous in situ measurements of methane $\left(\mathrm{CH}_{4}\right)$ fluxes from intact leaves and trunk of Japanese cypress

(Chamaecyparis obtusa Sieb. et Zucc) were conducted in a temperate forest from August 2009 to August 2010.

An automated closed chamber system, which was used to evaluate $\mathrm{CO}_{2}$ exchange between the atmosphere and forest ecosystems, was coupled to a laser-based instrument to monitor $\mathrm{CH}_{4}$ concentrations. Temporal changes in $\mathrm{CH}_{4}$ concentrations from the foliage and trunk were measured at one-second intervals during chamber closure to determine $\mathrm{CH}_{4}$ fluxes between the leaf and trunk surfaces and the atmosphere. While recent studies have suggested that some plants emit $\mathrm{CH}_{4}$ under aerobic conditions, emission or uptake of $\mathrm{CH}_{4}$ in detectable amounts with our experimental system, by intact leaves or the trunk of $C$. obtusa, was not significantly observed throughout the measurement period.

Key words: methane; plant emission; aerobic conditions; cypress; chamber method.

\section{Introduction}

Recent experiments conducted by Keppler et al. (2006) suggested that $\mathrm{CH}_{4}$ emissions from terrestrial plants under aerobic conditions could be a significant source of atmospheric $\mathrm{CH}_{4}$, and that global emissions could range from 62 to $236 \mathrm{Tg} \mathrm{CH}_{4} \mathrm{yr}^{-1}$. Using different scaling approaches, subsequent studies have revised

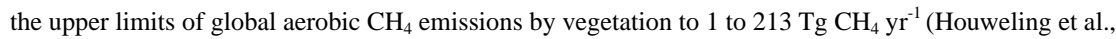
2006; Kirschbaum et al., 2006; Parsons et al., 2006; Butenhoff and Khalil, 2007; Ferreti et al., 2007; Megonigal and Guenther, 2008; Bloom et al., 2010). However, since the mechanisms underlying $\mathrm{CH}_{4}$ 
emission are still largely unknown, any extrapolations to the global scale are highly speculative. The data collected to date for in situ $\mathrm{CH}_{4}$ exchange in plant communities under aerobic conditions has been conflicting, with some studies reporting significant $\mathrm{CH}_{4}$ emissions (Cao et al., 2008; McLeod et al., 2008; Vigano et al., 2008; Wang et al., 2008; Brüggemann et al., 2009; Bruhn et al., 2009; Qaderi and Reid, 2009), while others have reported no significant emissions (Dueck et al., 2007; Beerling et al., 2008; Kirschbaum and Walcroft, 2008; Megonigal and Guenther, 2008; Bowling et al., 2009; Nisbert et al., 2009). Similarly, no consensus currently exists on the effect of ultraviolet (UV) irradiation on $\mathrm{CH}_{4}$ emissions (McLeod et al., 2008; Vigano et al., 2008, 2009; Bowling et al., 2009; Bruhn et al., 2009; Qaderi and Reid, 2009). Thus, despite numerous studies having been conducted on the microscopic mechanisms associated with $\mathrm{CH}_{4}$ production and the impact that these have on the global $\mathrm{CH}_{4}$ budget, the issue of $\mathrm{CH}_{4}$ exchange in plants under aerobic conditions has not yet been satisfactorily resolved.

In Japan, artificial plantations of Japanese cypress (Chamaecyparis obtusa Sieb. Et Zucc) cover up to $10 \%$ of the total Japanese forest area (Japan Forestry Agency, 2005). Investigating whether C. obtusa emits $\mathrm{CH}_{4}$ significantly is thus important to develop an emission inventory of $\mathrm{CH}_{4}$ in Japan and to understand its impact on the atmospheric $\mathrm{CH}_{4}$ budget. Recently, laboratory incubations investigating $\mathrm{CH}_{4}$ emission from detached leaves of $C$. obtusa in a temperate forest have been made (Kamakura et al., in press), in which leaf smaples were collected at different heights within the canopy. Estimated $\mathrm{CH}_{4}$ fluxes were close to zero, which were several orders of magnitude smaller than, for example, those from some other $\mathrm{C}_{3}$ plants as reported by Keppler et al.(2006). In this study, we for the first time made an attempt to estimate $\mathrm{CH}_{4}$ fluxes from intact leaves and trunk, which are rather than detached tissues, of $C$. obtusa over the whole season using an automated, closed-chamber system coupled to a laser-based instrument that allowed in situ real-time detection of $\mathrm{CH}_{4}$.

\section{Materials and methods}

\subsection{Study Site}

Methane flux measurements were conducted in the Kiryu Experimental Watershed (KEW) in Shiga 
Prefecture, central Japan, from August 2009 to August 2010. A detailed description of the site and a topographic map has been reported elsewhere (Ohkubo et al., 2007). The watershed has an area of 5.99 ha (1 ha $=10^{4} \mathrm{~m}^{2}$ ) and is mainly covered by Japanese cypress trees that were planted in 1959 (average height: $19 \mathrm{~m}$, basal area: $43 \mathrm{~m}^{-2} \mathrm{ha}^{-1}$, total basal area 1853 stems ha- ${ }^{-1}$ for $\left.92 \%\right)$. The air temperature, which was measured with a platinum thermometer (HMP45C, Vaisala) $29 \mathrm{~m}$ above the ground, ranged from -4.4 to $33.7^{\circ} \mathrm{C}$ during the study period. Precipitation was measured using a tipping bucket rain gauge (RT-5, Ikeda Keiki). Short-wave downward radiation in the region of 305 - $2800 \mathrm{~nm}$ was measured using an albedo meter (CM14, Kipp \& Zonen) $29 \mathrm{~m}$ above the ground.

\subsection{Experimental design}

We used an automated closed-chamber system to investigate $\mathrm{CH}_{4}$ exchange in intact leaves and trunk of C. obtusa using a foliage chamber (L340 mm $\times$ W500 mm $\times$ H200 mm) and a trunk chamber (L300 $\mathrm{mm} \times \mathrm{W} 300 \mathrm{~mm} \times \mathrm{H} 300 \mathrm{~mm}$ ), respectively. The same chamber system was used previously to measure ecosystem respiration (Ohkubo et al., 2007). The foliage chamber was placed in the lower canopy at a height of $17.2 \mathrm{~m}$ and enclosed a foliage surface area of $0.038 \mathrm{~m}^{2}$. The diameter at breast height (DBH; $1.2 \mathrm{~m}$ above the ground) and height of the sample tree were $0.18 \mathrm{~m}$ and $20.7 \mathrm{~m}$, respectively. The trunk chamber was placed at a height of $1.5 \mathrm{~m}$ and enclosed a trunk with a diameter of $180 \mathrm{~mm}$. The DBH and height of the sample tree were $0.18 \mathrm{~m}$ and $20.3 \mathrm{~m}$, respectively. Each chamber was constructed of acrylic resin. Using a quantum sensor (LP471PAR, DeltaOhm), the daily mean intensity of photosynthetically active wavelengths of radiation inside the chamber was estimated to be $95 \%$ of that outside the chamber. The chambers remain open most of the time and close for 120 seconds every 30 minutes. When the chamber is closed, a small ventilation fan ensures that the density of the gas within the chamber is uniform. During closure, air is drawn continuously from the target chamber through a polyfluoroacrylate tube (inner diameter: $4 \mathrm{~mm}$ ) using a diaphragm pump at a flow rate of approximately $1.8 \mathrm{~L} \mathrm{~min}^{-1}$, and is returned to the chamber. To analyze the $\mathrm{CH}_{4}$ concentration of the sampled air, some of the main flow $\left(0.7 \mathrm{~L} \mathrm{~min}{ }^{-1}\right)$ is passed through a membrane dryer (PD-50T-48, Perma Pure Inc.) to remove moisture before being diverted to a $\mathrm{CO}_{2} / \mathrm{H}_{2} \mathrm{O}$ analyzer (LI-840, 
LiCor) and a $\mathrm{CH}_{4}$ analyzer (FMA-100, Los Gatos Research). After analysis, the gas $\left(0.7 \mathrm{~L} \mathrm{~min}^{-1}\right)$ was returned to the main flow before returning to the chamber.

The $\mathrm{CH}_{4}$ analyzer used in this study employed cavity enhanced absorption spectroscopy with a diode laser of around $1.6 \mu \mathrm{m}$; the instrument permits interference-free real-time monitoring of $\mathrm{CH}_{4}$ concentration at atmospheric levels (Hendriks et al., 2008; Smeets et al., 2009). Before deploying the $\mathrm{CH}_{4}$ analyzer in the field, the instrumental performance was tested using the Allan variance method (e.g., Eugster and Plüss, 2010). The mixing ratio of $\mathrm{CH}_{4}$ in a dry compressed air cylinder (Masuda Medical Instruments) was measured over several hours with $1-\mathrm{Hz}$ resolution, and resultant time series of the data providing $2496 \pm 0.9 \mathrm{ppb}$ (mean \pm SD) were subjected to the Allan variance analysis. This assessment suggested that the Allan deviation of this analyzer was $0.7 \mathrm{ppb}$ with 1-s integration time (i.e., $\pm 0.03 \%$ against a background concentration of $2496 \mathrm{ppb}$ ), which is similar to that for the same kind of this instrument as reported recently (Eugster and Plüss, 2010). The overall precision of our measurement system was estimated using standard gas (1.773 ppm in synthetic air, Kyoto Teisan). The minimum measurable $\mathrm{CH}_{4}$ flux, estimated from the overall precision of our system at atmospheric levels of $\mathrm{CH}_{4}$, were \pm 0.77 and $\pm 0.11 \mathrm{nmol} \mathrm{m}^{-2} \mathrm{~s}^{-1}$ for foliage and trunk chambers, respectively. The zero offset of the $\mathrm{CH}_{4}$ analyzer was calibrated against pure nitrogen gas every day. The span of the $\mathrm{CH}_{4}$ analyzer was calibrated against standard gas every week. No serious drifts in zero and span readings were observed throughout the measurement period $(<1.0 \%)$. For the $\mathrm{CO}_{2} / \mathrm{H}_{2} \mathrm{O}$ analyzer, the zero offset was checked with pure nitrogen gas every day. The $\mathrm{CO}_{2}$ span was calibrated using a standard gas cylinder and water vapor using a dew-point generator (LiCor, LI-610).

Methane flux from foliage, $F_{\mathrm{f}}{ }^{\mathrm{CH} 4}\left(\mathrm{nmol} \mathrm{m}^{-2} \mathrm{~s}^{-1}\right)$, was calculated using the following equation (Ohkubo et al., 2007):

$$
F_{f}{ }^{C H 4}=\frac{\Delta C}{\Delta t} \times \frac{V_{f}}{A_{f}}
$$

where $V_{\mathrm{f}}\left(\mathrm{m}^{3}\right)$ is the chamber volume, $A_{\mathrm{f}}\left(\mathrm{m}^{2}\right)$ the enclosed foliage surface area $\left(0.038 \mathrm{~m}^{2}\right)$, and $\Delta C / \Delta t$ the rate of change in $\mathrm{CH}_{4}$ concentration inside the chamber $\left(\mathrm{C}\left(\mathrm{nmol} \mathrm{m}{ }^{-3}\right)\right)$ over time during chamber closure. Methane flux from trunk, $F_{\mathrm{t}}^{\mathrm{CH} 4}\left(\mathrm{nmol} \mathrm{m} \mathrm{s}^{-2}\right)$, was calculated using the following equation: 


$$
F_{t}^{C H 4}=\frac{\Delta C}{\Delta t} \times \frac{V_{t}}{V_{t}^{\prime}} \times K_{t}
$$

105 where $V_{\mathrm{t}}$ is the chamber volume excluding the enclosed trunk volume $\left(\mathrm{m}^{3}\right), V_{\mathrm{t}}^{\prime}$ the enclosed trunk volume $106\left(6.03 \times 10^{-3} \mathrm{~m}^{3}\right)$, and $\Delta C / \Delta t$ is as in Eq. (1). $K_{\mathrm{t}}\left(\mathrm{m}^{3} \mathrm{~m}^{-2}\right)$ is the coefficient converting the trunk chamber data into

average trunk respiration per unit of ground area at the site. This equation is based on the assumption that the efflux per trunk volume is uniform. In addition, $\mathrm{CO}_{2}$ fluxes from foliage $\left(F_{\mathrm{f}}{ }^{\mathrm{CO} 2}\right)$ and trunks $\left(F_{\mathrm{t}}{ }^{\mathrm{CO} 2}\right)$ were estimated as described for Eqs. (1-2). Positive values for $F_{\mathrm{f}}$ and $F_{\mathrm{t}}$ indicate emission, whereas negative values does uptake.

Figure 1 shows a typical trace of the raw time series obtained for $\mathrm{CH}_{4}$ and $\mathrm{CO}_{2}$ concentrations in the foliage, trunk, and three different soil chambers during their closures on 4 September, 2009 at 14:00 - 14:15 local time (LT); a program-controlled valve was used to switch between the gas sampling lines connected to the different five chambers at 3-minute intervals. While analysis of the soil data is beyond the scope of this paper, temporal changes in $\mathrm{CH}_{4}$ and $\mathrm{CO}_{2}$ concentrations in all of the chambers obtained $75 \mathrm{sec}$ after valve actuation were subjected to linear regression analysis to determine $\Delta C / \Delta t$ in Eqs. (1-2); all calculations considered the time lag associated with the movement of sampled air to the analyzers and the gas flush times of the optical cavity in the analyzers.

A potential problem associated with determining $\Delta C / \Delta t$ was the presence of artifacts related to the apparent dilution of $\mathrm{CH}_{4}$ due to the increase in water molecules derived from the transpiring leaves in the foliage chamber. In this study, a membrane dryer was used to remove water vapor from the air samples prior to $\mathrm{CH}_{4}$ analysis. However, the drying efficiency of such dryers has been reported to be dependent upon operational conditions (Leckrone and Haynes, 1997). We therefore measured the residual water vapor exiting the membrane dryer using the LI-840 analyzer (Fig. 1), and the data were used to compensate for the observed temporal changes in $\mathrm{CH}_{4}$ concentrations. The mixing ratio of residual water vapor was less than 4.8 permille and the rate of increase during chamber closure was less than 0.01 permille $\mathrm{s}^{-1}$ over the entire observation period. 


\section{Results and discussion}

\subsection{Foliage}

Figure 2 shows an example of temporal variations in $\mathrm{CH}_{4}$ fluxes between the foliage and trunk of $C$. obtusa and the atmosphere, as well as $\mathrm{CO}_{2}$ fluxes and changes in air temperature and solar radiation during 1 8 September, 2009. The quoted uncertainty in the individual $\mathrm{CH}_{4}$ flux values was equivalent to two standard deviations from the least-squares regression and the uncertainty in the measurement of $\mathrm{CH}_{4}$ concentration. The $\mathrm{CO}_{2}$ fluxes from foliage followed a diel cycle in response to photosynthetic uptake and respiratory release, but such a diel cycle was not clearly observed in the $\mathrm{CH}_{4}$ fluxes. The $\mathrm{CH}_{4}$ fluxes were very low and around or below the minimum detection limit of our instrumentation. Very low fluxes are not contradictory to the results reported by Kamakura et al. (in press), although our experimental design is different from their study. The $\mathrm{CH}_{4}$ flux distributions in this study were not significantly different from zero (p-value $>0.01$, two-tailed t-test). In order to investigate the seasonal characteristics of the $\mathrm{CH}_{4}$ flux distributions, the obtained data were summed over three-month intervals as shown in Figure 3. Results indicate that seasonal variation in the flux distributions was unclear $(\mathrm{p}>0.01)$ and intact leaves of $C$. obtusa did, in our experimental system, neither emit nor absorb detectable amounts of $\mathrm{CH}_{4}$ for all seasons (within $\pm 1.0 \mathrm{nmol} \mathrm{m}{ }^{-2} \mathrm{~s}^{-1}$ ), with the differences from zero statistically indistinguishable $(\mathrm{p}>0.01)$. No clear diel or seasonal changes in $F_{\mathrm{f}}{ }^{\mathrm{CH} 4}$ were observed with our experimental system, suggesting that changes in air-temperature and solar radiation (at least wavelengths longer than about $380 \mathrm{~nm}$, see following paragraph) do not control the emission of $\mathrm{CH}_{4}$ from leaves of C. obtusa at rates detectable in our system.

Interestingly, various authors have reported that $\mathrm{CH}_{4}$ emissions from the structural component pectin, as well as from fresh and dried leaf material, occur in response to UV irradiation (McLeod et al., 2008; Vigano et al., 2008, 2009, Bruhn et al., 2009; Qaderi and Reid, 2009). On the other hand, Bowling et al. (2009) reported that no evidence was found for a significant foliar $\mathrm{CH}_{4}$ source in the vegetation canopy under high UV irradiance conditions. Unfortunately, in this study, we were unable to examine whether such UV-induced, non-enzymatic processes contribute to $\mathrm{CH}_{4}$ emissions because the chambers were constructed of acrylic, which filters out most of the solar UV (the cut-off wavelength of $380 \mathrm{~nm}$ was estimated using a UV-VIS 
spectrometer (U-2001, Hitachi)). Using chambers constructed of UV-transparent glass would enable us to address this issue. On the other hand, we have also been investigating $\mathrm{CH}_{4}$ exchange on a canopy scale in KEW using a technique employing relaxed eddy accumulation; the obtained results have revealed the existence of seasonal variations in $\mathrm{CH}_{4}$ flux with emission (from the forest to the atmosphere) maxima occurring in September to October and uptake (from the atmosphere to the forest) maxima occurring in May to June (Sakabe et al., 2011). Since surface UV intensity on Honshu Island in Japan peaks near the summer solstice and troughs near the winter solstice, even if UV light-induced processes promoted the emission of $\mathrm{CH}_{4}$ from intact $C$. obtusa leaves, such emissions would not markedly affect $\mathrm{CH}_{4}$ flux on a canopy scale.

\subsection{Trunk}

The results obtained for trunk were similar to those for foliage, i.e. as shown in Figs 2 and 3, no significant emission or uptake of $\mathrm{CH}_{4}$ was recorded and no diel or seasonal changes were evident over the course of the study (wthin $\pm 0.14 \mathrm{nmol} \mathrm{m} \mathrm{m}^{-2}$ ), with the differences from zero statistically indistinguishable (p $>0.01$ ). The $\mathrm{CH}_{4}$ fluxes were very low and around or below the minimum detection limit of our instrumentation. Recent incubation studies by Wang et al. $\left(2008\right.$, 2009) have shown that $\mathrm{CH}_{4}$ emissions from detached xerophyte stems under aerobic conditions are both complex and vary depending on the species. Thus, much still remains to be done with regard to clarifying $\mathrm{CH}_{4}$ exchange between tree trunks and the atmosphere under aerobic conditions.

\section{Acknowledgments}

The authors thank to Drs. Masayuki Ito (Kyoto Univ.) and Mai Kamakura (Nara Womens’ Univ.) for fruitful discussions. This study was supported in part by a Grant-in-Aid from the MEXT. The authors are grateful to the anonymous referees for their constructive comments.

\section{References}

Beerling, D.J., Gardiner, T., Leggett, G., McLeod, A., Quick, W.P., 2008. Missing methane emissions from 
leaves of terrestrial plants. Glob. Change Biol. 14, 1821-1826.

Bloom, A.A., Lee-Taylor, J., Madronich, S., Messenger, D.J., Palmer, P.I., Reay, D.S., McLeod, A.R., 2010. Global methane emission estimates from ultraviolet irradiation of terrestrial plant foliage. New Phytol. 187, 417-425.

Bowling, D.R., Miller, J.B., Rhodes, M.E., Burns, S.P., Monson, R.K., Baer, D., 2009. Soil, plant, and transport influences on methane in a subalpine forest under high ultraviolet irradiance. Biogeosciences $6,1311-1324$.

Brüggemann, N., Meier, R., Steigner, D., Zimmer, I., Louis, S., Schnitzler, J.P., 2009. Nonmicrobial aerobic methane emission from poplar shoot cultures under low-light conditions. New Phytol. 182, 912-918.

Bruhn, D., Mikkelsen, T.N., Obro, J., Willats, W.G.T., Ambus, P., 2009. Effects of temperature, ultraviolet radiation and pectin methyl esterase on aerobic methane release from plant material. Plant Biol. 11, 43-48.

Butenhoff, C.L., Khalil, M.A.K., 2007. Global methane emissions from terrestrial plants. Environ. Sci. Tech. 41, 4032-4037.

Cao, G.M., Xu, X.L., Long, R.J., Wang, Q.L., Wang, C.T., Du, Y.G., Zhao, X.Q., 2008. Methane emissions by alpine plant communities in the Qinghai-Tibet Plateau. Biol. Lett. 4, 681-684.

Dueck, T.A., de Visser, R., Poorter, H., Persijn, S., Gorissen, A., de Visser, W., Schapendonk, A., Verhagen, J., Snel, J., Harren, F.J.M., Ngai, A.K.Y., Verstappen, F., Bouwmeester, H., Voesenek, L., van der Werf, A., 2007. No evidence for substantial aerobic methane emission by terrestrial plants: a C-13-labelling approach. New Phytol. 175, 29-35.

Eugster, W., Plüss, P., 2010. A fault-tolerant eddy covariance system for measuring $\mathrm{CH}_{4}$ fluxes. Agric. Forest Meteorol. 150, 841-851.

Ferretti, D.F., Miller, J.B., White, J.W.C., Lassey, K.R., Lowe, D.C., Etheridge, D.M., 2007. Stable isotopes provide revised global limits of aerobic methane emissions from plants. Atmos. Chem. Phys. 7, 237-241.

Hendriks, D.M.D., Dolman, A.J., van der Molen, M.K., van Huissteden, J., 2008. A compact and stable eddy 
covariance set-up for methane measurements using off-axis integrated cavity output spectroscopy. Atmos. Chem. Phys. 8, 431-443.

Houweling, S., Röckmann, T., Aben, I., Keppler, F., Krol, M., Meirink, J.F., Dlugokencky, E.J., Frankenberg, C., 2006. Atmospheric constraints on global emissions of methane from plants. Geophys. Res. Lett.

Japan Forestry Agency, 2005. Annual report on trends of forest and forestry. In: The Ministry of Agriculture,

$$
\text { Forestry and Fisheries of Japan (Ed.). }
$$

Kamakura, M., Kosugi, Y., Nakagawa, R., Itoh, M., 2011. Methane flux of leaves in a tropical rainforest and a temperate conifer forest. J. Agric. Meteorol., in press.

Keppler, F., Hamilton, J.T.G., Brass, M., Röckmann, T., 2006. Methane emissions from terrestrial plants under aerobic conditions. Nature 439, 187-191.

Kirschbaum, M.U.F., Bruhn, D., Etheridge, D.M., Evans, J.R., Farquhar, G.D., Gifford, R.M., Paul, K.I., Winters, A.J., 2006. A comment on the quantitative significance of aerobic methane release by plants. Funct. Plant Biol. 33, 521-530.

Kirschbaum, M.U.F., Walcroft, A., 2008. No detectable aerobic methane efflux from plant material, nor from adsorption/desorption processes. Biogeosciences 5, 1551-1558.

Leckrone, K.J., Hayes, J.M., 1997. Efficiency and temperature dependence of water removal by membrane dryers. Anal. Chem. 69, 911-918.

McLeod, A.R., Fry, S.C., Loake, G.J., Messenger, D.J., Reay, D.S., Smith, K.A., Yun, B.W., 2008. Ultraviolet radiation drives methane emissions from terrestrial plant pectins. New Phytol. 180, 124-132.

Megonigal, J.P., Guenther, A.B., 2008. Methane emissions from upland forest soils and vegetation. Tree Physiol. 28, 491-498.

Nisbet, R.E.R., Fisher, R., Nimmo, R.H., Bendall, D.S., Crill, P.M., Gallego-Sala, A.V., Hornibrook, E.R.C., Lopez-Juez, E., Lowry, D., Nisbet, P.B.R., Shuckburgh, E.F., Sriskantharajah, S., Howe, C.J., Nisbet, E.G., 2009. Emission of methane from plants. Proceedings of the Royal Society B-Biological Sciences 276, 1347-1354. 
Ohkubo, S., Kosugi, Y., Takanashi, S., Mitani, T., Tani, M., 2007. Comparison of the eddy covariance and automated closed chamber methods for evaluating nocturnal $\mathrm{CO}_{2}$ exchange in a Japanese cypress forest. Agricul. Forest Meteorol. 142, 50-65.

Ohte, N., Tokuchi, N., Suzuki, M., 1997. An in situ lysimeter experiment on soil moisture influence on inorganic nitrogen discharge from forest soil. J. Hydrol. 195, 78-98.

Qaderi, M.M., Reid, D.M., 2009. Methane emissions from six crop species exposed to three components of global climate change: temperature, ultraviolet-B radiation and water stress. Physiol. Plant. 137, 139-147.

Parsons, A.J., Newton, P.C.D., Clark, H., Kelliher, F.M., 2006. Scaling methane emissions from vegetation. Trends in Ecology and Evolution 21, 423-424.

Sakabe, A., Hamotani, K., Kosugi, Y., Ueyama, M., Takahashi, K., Kanazawa, A., Itoh, M., 2011. Measurement of methane flux over an evergreen coniferous forest canopy using a relaxed eddy accumulation system with tunable diode laser spectroscopy detection. Theor. Appl. Climatol. (in press)

Smeets, C., Holzinger, R., Vigano, I., Goldstein, A.H., Röckmann, T., 2009. Eddy covariance methane measurements at a Ponderosa pine plantation in California. Atmos. Chem. Phys. 9, 8365-8375.

Vigano, I., van Weelden, H., Holzinger, R., Keppler, F., McLeod, A., Röckmann, T., 2008. Effect of UV radiation and temperature on the emission of methane from plant biomass and structural components. Biogeosciences 5, 937-947.

Vigano, I., Röckmann, T., Holzinger, R., van Dijk, A., Keppler, F., Greule, M., Brand, W.A., Geilmann, H., van Weelden, H., 2009. The stable isotope signature of methane emitted from plant material under UV irradiation. Atmos. Environ. 43, 5637-5646.

Wang, Z.P., Han, X.G., Wang, G.G., Song, Y., Gulledge, J., 2008. Aerobic methane emission from plants in the Inner Mongolia steppe. Environ. Sci. Tech. 42, 62-68.

Wang, Z.P., Gulledge, J., Zheng, J.Q., Liu, W., Li, L.H., Han, X.G., 2009. Physical injury stimulates aerobic methane emissions from terrestrial plants. Biogeosciences 6, 615-621. 


\section{Figure captions}

260 Figure 1 Typical time series for $\mathrm{CH}_{4}$ and $\mathrm{CO}_{2}$ concentrations in foliage, trunks and three different soil chambers on 4 September 2009, from 14:00 to 14:15 LT. Concentration of residual water vapor exiting the membrane dryer was also recorded (see text). At intervals of three minutes, a program-controlled valve switched between the lines connecting the different measurement chambers. The target chamber closed $30 \mathrm{sec}$ after valuve actuation. $\mathrm{CH}_{4}$ concentrations were recorded at one-second intervals, while $\mathrm{CO}_{2}$ and $\mathrm{H}_{2} \mathrm{O}$ concentrations at 10 -second intervals. Analysis of soil data is beyond the scope of this paper.

Figure 2 Temporal variations in $\mathrm{CH}_{4}$ and $\mathrm{CO}_{2}$ fluxes between leaves or trunk and the atmosphere, and air temperature and solar radiation from September 1 to 8, 2009. Positive flux values indicate emission from leaves/trunk to the atmosphere, whereas negative values uptake. No precipitation was observed during this period. Arrows in the margin indicates the minimum measureable fluxes (see text).

Figure 3 Box-and-whisker plots depicting seasonal $\mathrm{CH}_{4}$ fluxes from leaves $\left(F_{\mathrm{f}}^{\mathrm{CH} 4}\right)$ and trunk $\left(F_{\mathrm{t}}^{\mathrm{CH} 4}\right)$. Data were divided into autumn (1 Sept., 2009 to 30 Nov., 2009; $n=4145$ for foliage, $n=4053$ for trunk), winter (1 Dec., 2009 to 28 Feb., 2010; $n=1248$ for foliage, $n=4102$ for trunk), spring (1. Mar., 2010 to 31 May, 2010; $n=4175$ for foliage, $n=4367$ for trunk), and summer (1 June, 2010 to 31 Aug., 2010; $n=1375$ for foliage, $n$ $=2153$ for trunk). Boxes enclose all values between the $25^{\text {th }}$ and $75^{\text {th }}$ percentiles, whereas whiskers encompass all values within the $5^{\text {th }}$ to $95^{\text {th }}$ percentile range. Solid horizontal bars in the boxes indicate median values and horizontal broken bars indicate the mean values. Mean values for the foliage data are 0.007, $-0.016,-0.003$, and $0.008 \mathrm{nmol} \mathrm{m} \mathrm{s}^{-1}$ for autumn, winter, spring and summer, respectively. Mean values of the trunk data are indicate the minimum measureable fluxes (see text). 


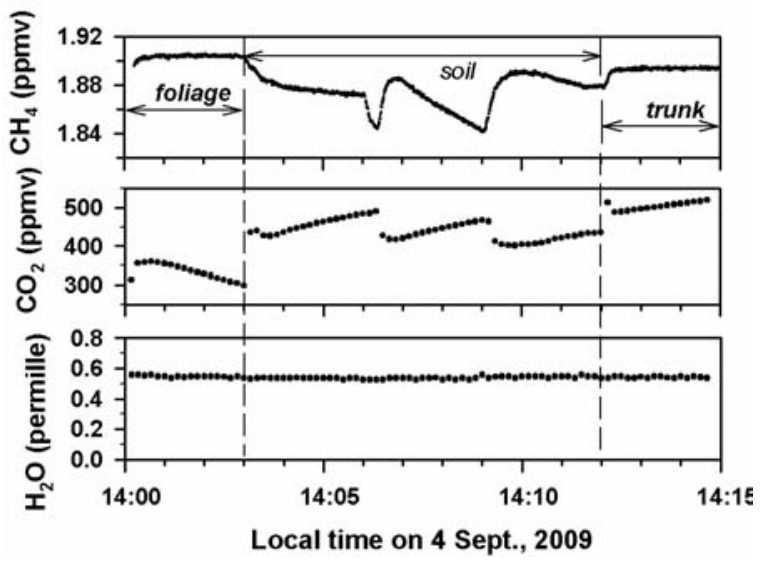

Figure 1 Takahashi et al. 

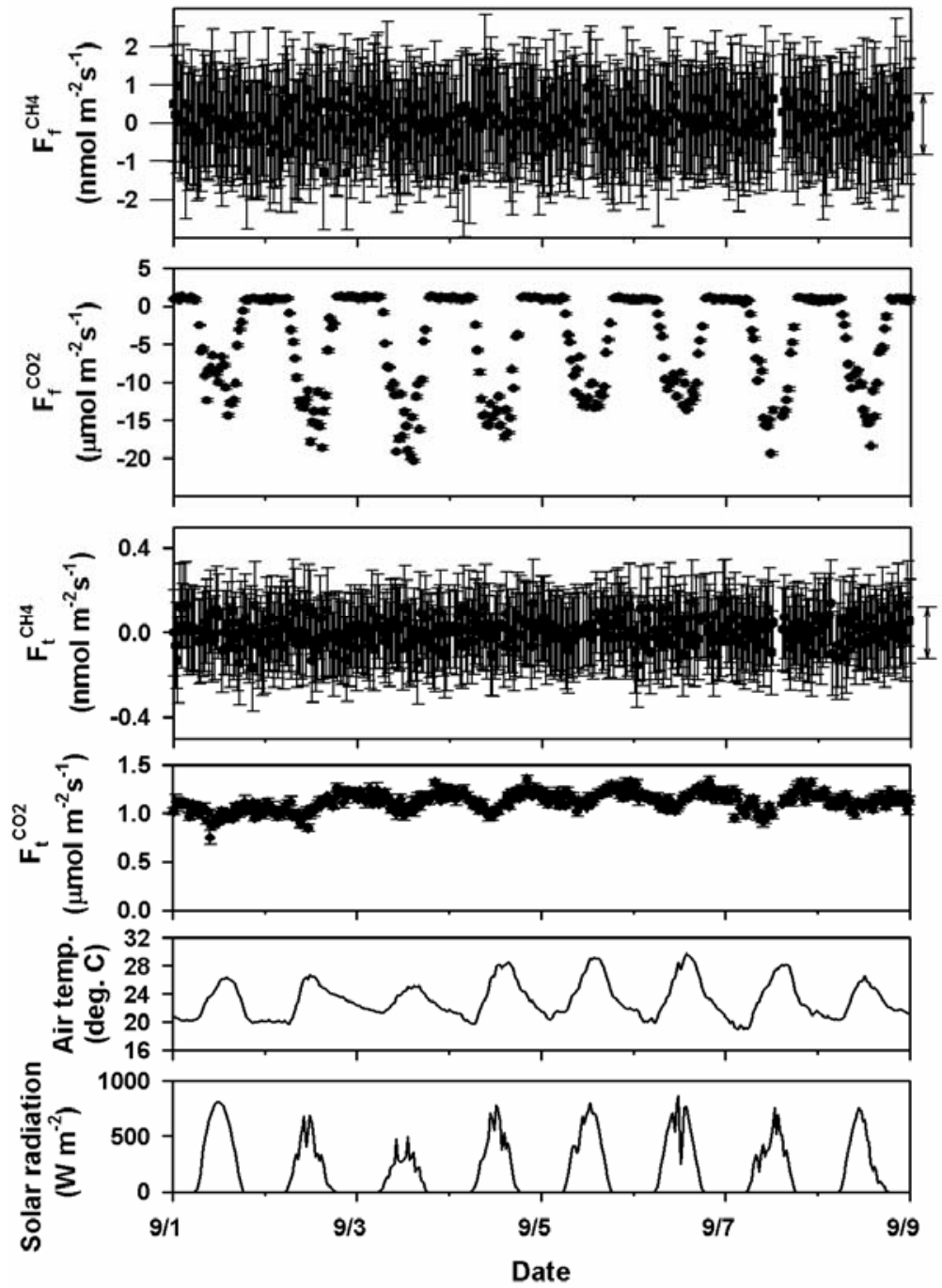

286 Figure 2 Takahashi et al. 

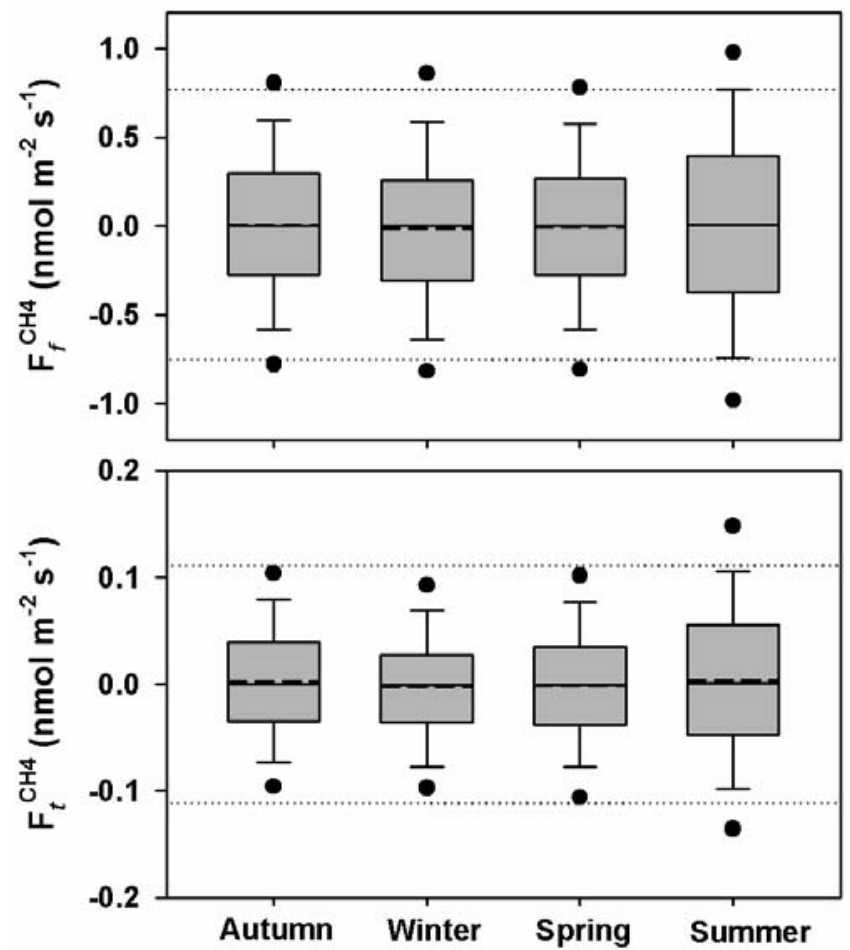

Figure 3 Takahashi et al. 